\section{Applications in Cross-Curriculum Teaching The Synthesis of the Design Studio and Building Technology Seminar}

\author{
John Enright, AIA \\ University of Southern California
}

\begin{abstract}
:
"Change or perish. You need to prepare yourself for a profession that you are not going to recognize a decade from now."

Thom Mayne, Remarks on building information modeling at the 2005 AIA Convention, Las Vegas, NV
\end{abstract}

Today architects are faced with new challenges involving Integrated Project Delivery and associated digital technologies that are rapidly changing the way architects work. Collaboration is the key to this new way of working as architects discover that the management of building information requires new skills and methods in design.

How do educators respond to this call? How do we prepare a future generation of architects to thrive within a rapidly changing profession?

Given these new models for project delivery currently being utilized by the profession, a new pair of courses was created at the Southern California Institute of Architecture (SCl_Arc) for the integration of the design curricula with a building technology course by emphasizing teamwork and the use of three-dimensional software. The aim was to develop new skill-sets for students while maintaining a deep understanding of design and built form. Educators have long struggled with traditional architectural curricula that inherently separate design and technology courses. This bifurcation, often times convenient and useful for the organization of a school and curriculum, is of course at odds with the "comprehensive" nature of architectural education that is so strived for in most programs.

This paper serves to show examples of an attempt to address this serious issue within the first professional graduate school curriculum (3 1/2 year M.ARCH) by bridging both the second year design and technology classes over a two semester span. The goals of the two courses were; to bridge the gap between design and technology pedagogy, develop collaborative tools for students, investigate a comprehensive understanding of the integration of building systems, and to finally produce a set of documents that demonstrate this ability and use appropriate three-dimensional software to facilitate the investigation.

It is helpful to set the stage on the importance of this shift of educational methodology by outlining first the context of the current environment both within the profession and the academic realms. Finally, I will attempt to reflect on the methods employed and analyze the pros and cons of the endeavor and discuss possible improvements.

\section{The professional context: AlA Initiatives}

There has been in recent years much discussion regarding the professions movement towards a more integrated and collaborative method of project delivery. A series of conferences and symposia have begun to address new models of collaboration through Building Information Modeling software that is becoming pervasive within the fields of architecture, engineering, manufacturing, and construction (1). The movement towards a fully integrated three-dimensional shared building model strategy has numerous benefits to clients, architects and builders, but more importantly, it is changing the way architects work by requiring new collaborative tools beyond the software. As Norman Strong has stated, "Technological evolution coupled with owner demand for better, faster, less costly construction projects and more effective processes are driving change in the construction industry. These changes are revolutionary in nature. They will transform practice as we know it."(2)

The AIA's response to this need for re-tooling the profession has been to adopt "Integrated Project Delivery" that is inherently more comprehensive than simply the associated software (BIM.) This has resulted in not only a set of guidelines for architects to begin to understand the issues at hand, but also a new set of architect / owner / contractor agreements offered by the AIA. This speaks to the pervasive paradigm shift occurring in the profession, a fundamental change is occurring that requires nothing less than the complete reworking of the relationship and roles of an architect, owner and builder. "Integrated Project Delivery uses business structures, practices, and processes to collaboratively use the talents and insights of all participants in the design, construction and fabrication process." (3) This shift is critical to understanding the role of our coursework as we began to address the re-connection of the design and technology pedagogy of the school.

\section{Construction Industry Perspective}

It is not only the AIA of course who is grappling with the changing modes of project delivery. The construction industry, some may argue, is well ahead of the curve regarding adoption of new means to better construct 
buildings and deliver more value, less waste, and better integrated projects. The Construction Users Roundtable (CURT) has focused extensively on the topic, and associated industry organizations continue to study these implications. (4)

On a recent visit to a construction site in Los Angeles with my students, we were shown a large saltwater aquarium project that was under construction. The project was a concrete structure, with a variety of complex mechanical and plumbing systems, many fabricated in stainless steel because of the corrosive salt-water environment. The contractor team explained to us that the construction documents were completed by the architect using standard two-dimensional working drawings which were the basis of the bid and award to the contractor. What was special about this project, however, was the construction team's decision to take the entire set of construction documents and translate these into a complete working 3D Building Information Model. This was the first time the company had delved into BIM, and they hired new staff that worked in the construction trailer at the project site. Within a few months they had the entire project completed in the BIM model, they further required that all of their sub-contractors use the model and submit shop drawings within the BIM environment. Their enthusiasm for the process and the subsequent ease of coordinating the project were laid out for us as they showed how the model was used for staging the construction timeline, quantity take-offs for budgeting, and the obvious savings in time and errors with a fully coordinated and dynamic 3D model. The most powerful image was the last slide of the presentation, however, where a photograph of a mechanical room was displayed with the typical maze of pipes, ductwork, electrical conduit, and HVAC ducts. Next to that photograph was the exact same rendered view from the BIM model, with all of the same equipment exactly in place, even including the pipe elbows and unistrut hangers. The completeness of the BIM model was obviously impressive, but perhaps most telling of this example was the notion that a contractor had taken the initiative that the architect had not. As the presenter concluded somewhat ominously, "I'm not sure what we need architects for anymore."

Of course the argument for the need for the role of the architect is larger than simply coordinated mechanical rooms and efficient delivery systems, but the example is more and more prevalent as architects continue to fail to adapt to this changing environment. Exposing students to this issue is imperative to prepare them for the environment that they will soon enter. As educators we must be able to balance both the pressing industry needs of efficiency and production with our continued research into design and making as it pertains to the positive effect that architecture has on our built environment.

\section{The academic context:}

\section{The Boyer Report}

"The Boyer Report", an independent study of architectural education first published in 1996, outlined many of the same issues that we see today as needing to be addressed in architectural education. Some of those findings still ring true today; "Most disappointingly, many design studios seem not to be living up to their vast potential as settings where integration of knowledge might be fostered. ...lack of integration of technical and practical knowledge into design work is probably the single most widespread area of concern." And as Bill Miller was quoted in the report, "The studio is an environment of synthetic activity should expand its focus beyond the formal and aesthetic. Schools should treat the entire curriculum holistically and integratively, ensuring that core areas (design, technology, history, practice) work in tandem with each other. The separation of these core content areas is artificial and needs reconsideration." The Boyer Report went on to conclude, "Making connections, both within the architecture curriculum and between architecture and other disciplines on campus, is, we believe, the single most important challenge confronting architectural programs." (5)

\section{NAAB, ACSA initiatives}

The recent developments the profession faces discussed previously have only served to exacerbate this issue within the academic context. Topics regarding integration of curricula, the design studio, and technical coursework are being discussed still today, but with a renewed sense of urgency given the professional context. The challenges are two-fold, how do we continue to teach the various aspects of design and technology while constructing methods that better integrate these disciplines based on emerging models growing in the profession? Daniel Friedman has put it eloquently, "What would happen if schools recombined the elements of instruction based on hybrid models - newly formulated around shifting topics, repertoires, vocabularies, skills, and sequences, in dialogue with changing requirements and conditions for practice, driven by new critical methodologies, commensurate with emerging technology?"(6)

The AIA's White Paper for NAAB Accreditation Review Conference attempted to focus the various professional issues related to integrated practice as they pertain to future architectural education requirements. The paper outlined three specific topics that are pertinent to the topic of this investigation;

"Are the traditional divisions of technology and design instruction irrelevant given this new model of a shared, dynamic, and collaborative system?"

"How can new modeling and simulation tools be used to support interdisciplinary studies?"

"How will educators teach the collaborative tools necessary to prepare students for this new way of working?"(7) 
The ACSA/AIA Cranbrook 2007: Integrated Practice and the Twenty-first Century Curriculum conference gathered educators, professionals, and construction industry leaders to address these issues as well. Discussion groups and presentations centered on how architectural education will change in the future and how educators will develop new methods to adapt to this change. Edward Allen, in his closing remarks, made two points that are pertinent to the topic this paper is focusing on. The first point is the understanding that the vast knowledge of building technology is almost impossible to teach in a single architectural curriculum, let alone a pair of courses. Rather, as he stated, "I have a wonderfully liberating piece of advice that should make it worthwhile for everybody to have attended this session this afternoon. It's not my idea. It comes from an instructor at the Massachusetts Institute of Technology (MIT), and it is in a teaching manual that MIT provides to all its faculty members. This is the advice: Don't try to cover your subject. It's impossible. Instead, you should uncover an important portion of the subject and teach your students how to learn it for themselves." His second point addresses the subject of this paper directly, "I also want to address a pet topic of mine, a tragic situation that exists in most schools - the great gulf that lies between the technical courses and the design courses. This gulf has occurred largely because of a misunderstanding that the studios are where art is taught and the technical courses are where science is taught. Architectural design is not art. It is design. It is the solving of human problems through the creation of form. Technology is not Science. Technology is design." (8)

In light of Edward Allen's comments then, the goal in our coursework was to simultaneously give students the proper tools to learn how technology and design are inexorably linked by building on their design studio work as a platform, and to encourage and enable teamwork in this environment. This was done with the understanding that we could not possibly attempt to teach the full breadth of all types of design and building technology, but rather to use the students experience through their specific projects to teach them a method that could be applied throughout their careers.

\section{The synthesis of the design studio and building technology seminar applied: \\ The Two-Semester Approach}

Our attempt at integrating the design and technology work within the school began with a comprehensive rethinking of the 2 nd year curriculum in the graduate school. The first step to accomplish this was to overlap the design instructors with the technology seminar. Four design instructors comprised studios of twelve students each in the fall semester, then two of those instructors (the author and one other instructor) were assigned the technology seminar in the spring semester consisting of the entire class of forty-eight students. This overlap proved critical in the tracking of both the students and their work over the academic year. The second major difference was to think of the whole academic year as a continuous line of development from the design studio to the technology seminar by

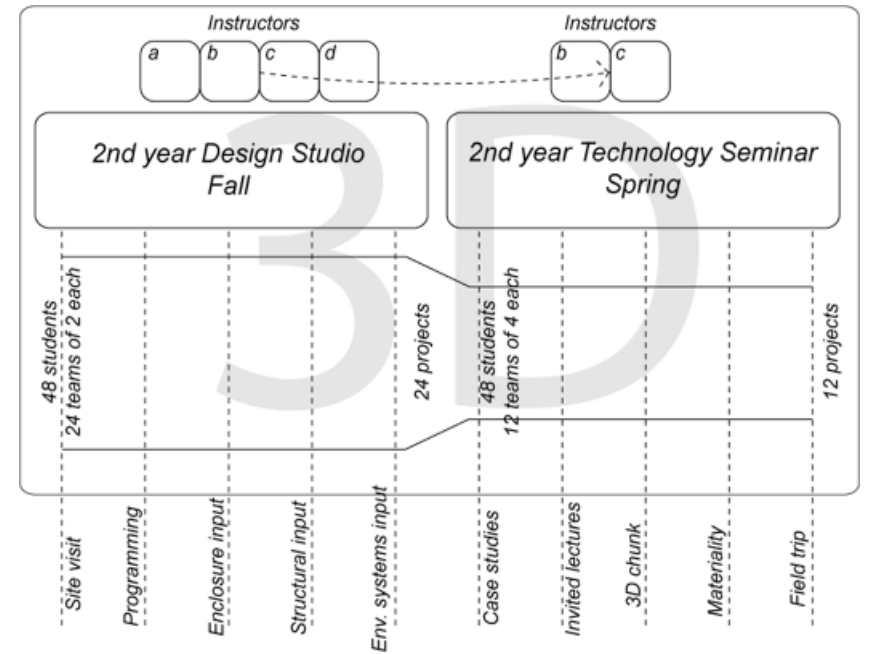

One year curriculum diagram

using the projects developed in the fall as a basis for the investigations in the spring. The fall design studio was a comprehensive building project, the students first in the curriculum, that also encouraged teamwork by students working in pairs for the bulk of the semester.

What distinguished this approach from previous courses in the curriculum was the emphasis that design and technology are not separate entities, but rather are integral pieces in the development of architectural inquiry. The use of instructors known for their design work emphasized this to the students, hopefully beginning to erode in their minds the idea that these two topics are separate specialties within the discipline.

\section{The Design Studio}

The design studio pedagogy focused on building performance issues as they related to theory, form, technology, and building program. This notion of performative architecture was valuable because it both bridged the technical and the abstract. As David Leatherbarrow has stated, "For a theory of performativity we should seek nothing more and nothing less: the instrumental reason and the rationality on which it depends, plus situated understanding that discovers in the particulars of a place, people, and purpose the unfounded conditions that actually prompt, animate and conclude a building's performances."(9)

A strong emphasis on 3D software and physical models was also critical in testing these various notions of performance from the beginning of the semester. Students were also introduced along the semester to invited guests that gave input on structure and environmental systems during the semester. These guests acted as "rovers" over the four studios with the design instructors to pollinate their respective specialties in informal desk crits and pinups. The students then integrated this input into their modeling as the project progressed. 


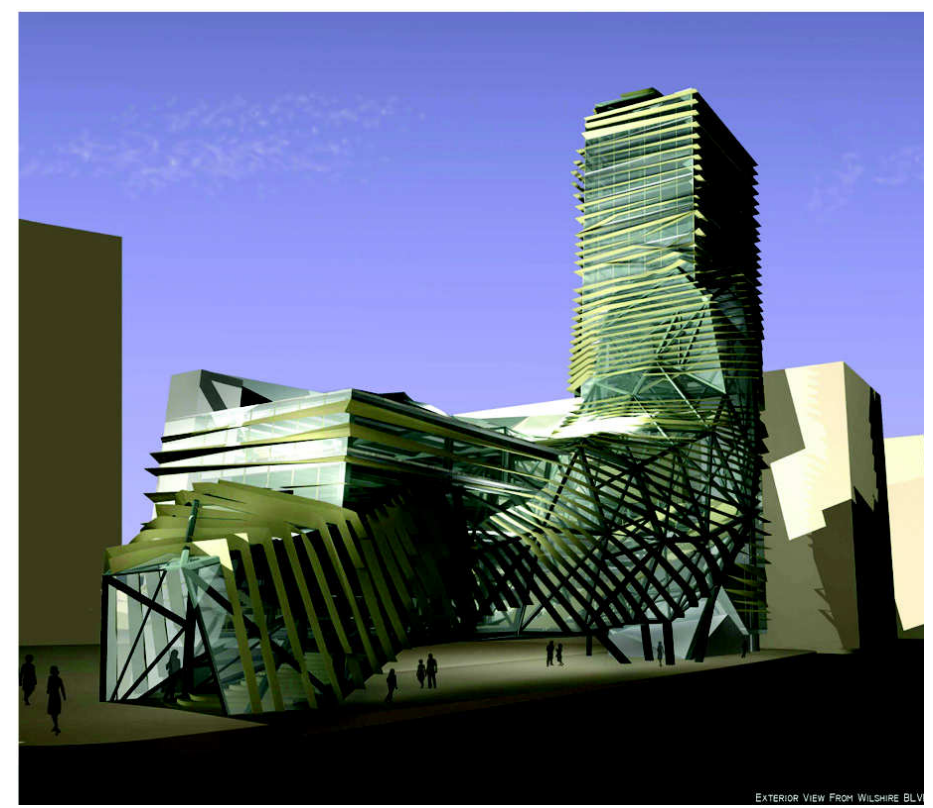

Project 1: Design Studio rendering

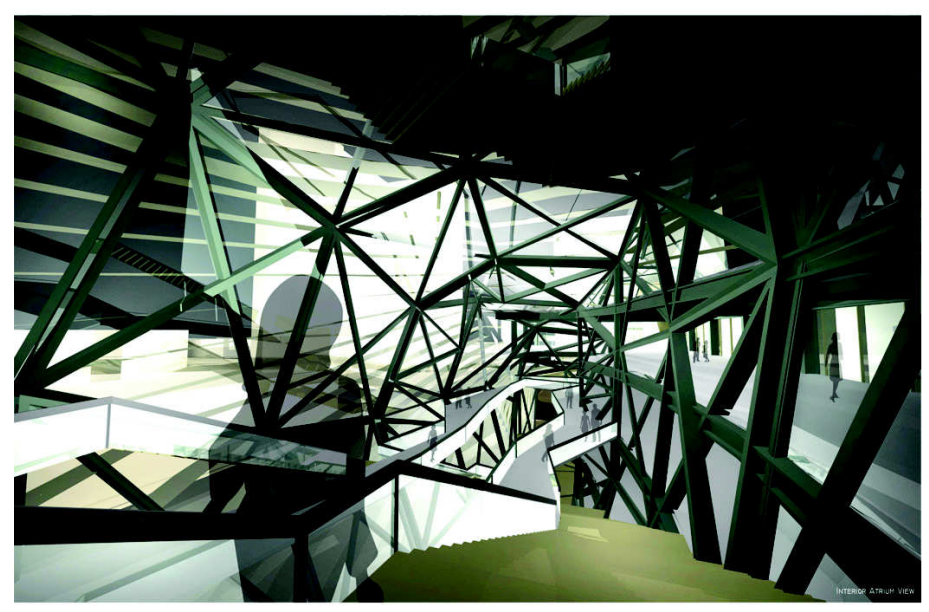

Project 1: Design Studio interior rendering

It should be noted that the while the four studio instructors' individual interests, research and design theories differed, the overall goal of encouraging and challenging students to develop comprehensive building projects was shared. The design culture at $\mathrm{SCl} \_$Arc is one of experimentation and questioning of contemporary architecture and the resulting design studio work reflects an energy and quest for alternative notions of space and from. This emphasis on design as a critical endeavor created quite challenging projects for the students, many of which were robust inquiries into new models of form and structure that included a good amount of complexity.

\section{The Technology Seminar}

The key aspect of the cross-curricular method was to use the design projects in the spring semester as a basis for further technical development in the building technology seminar. Twelve projects from the design studio were chosen based on their overall development, challenging complexity, and general excellence. The authors of these twelve groups then teamed up with two others from the class to create teams of four. It should be noted that all of the twelve projects were fully developed in 3D software and had basic notions of structure and building enclosure, but varying levels of materiality or detailed notions of building systems and enclosure. In professional terms, these were well developed "schematic designs." The computational software used for the bulk of the design and technology courses was not specifically geared to teaching one specific software type, but rather students were exposed to a variety of software technologies and used them as they saw fit for particular purposes.

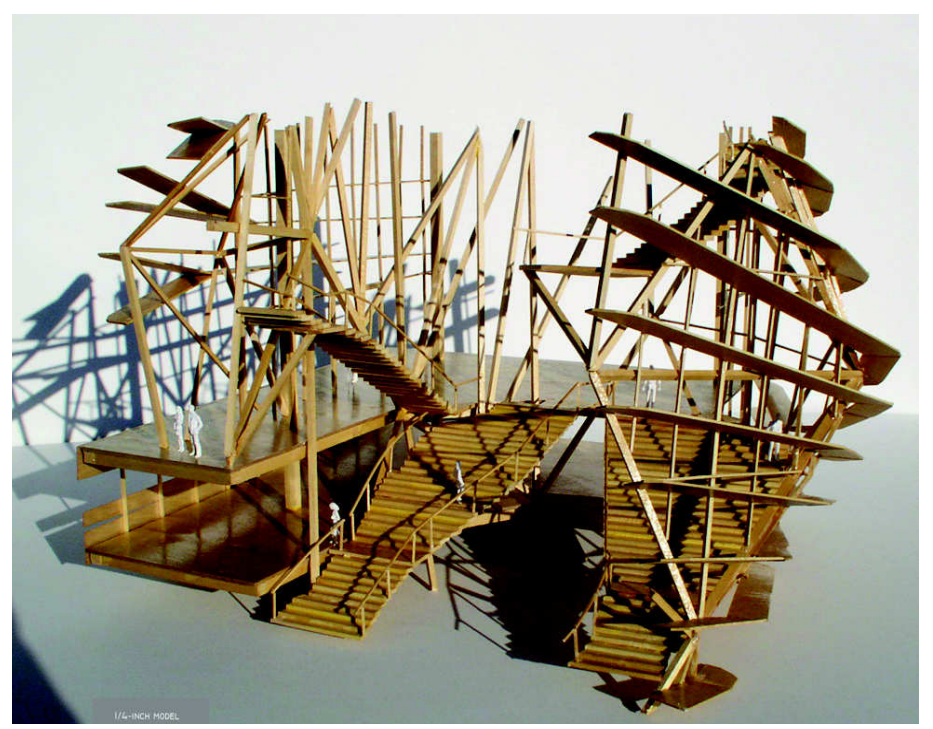

Project 1: Design Studio study model

The technology seminar was divided into two parts, the first comprised robust and in-depth case studies of built projects the instructors had direct involvement in from design to construction. These case studies, along with invited lecturers, were presented and discussed in terms of their construction and the innovative methods of documentation of complex form. We took advantage of Los Angeles' unique professional environment of architects who are both known for innovation in design and their ability to use new forms of technology to further their architectural agendas. These included invited architects from the offices of Frank $O$. Gehry \& Associates, Morphosis Architects, and COOP Himmelblau. A 


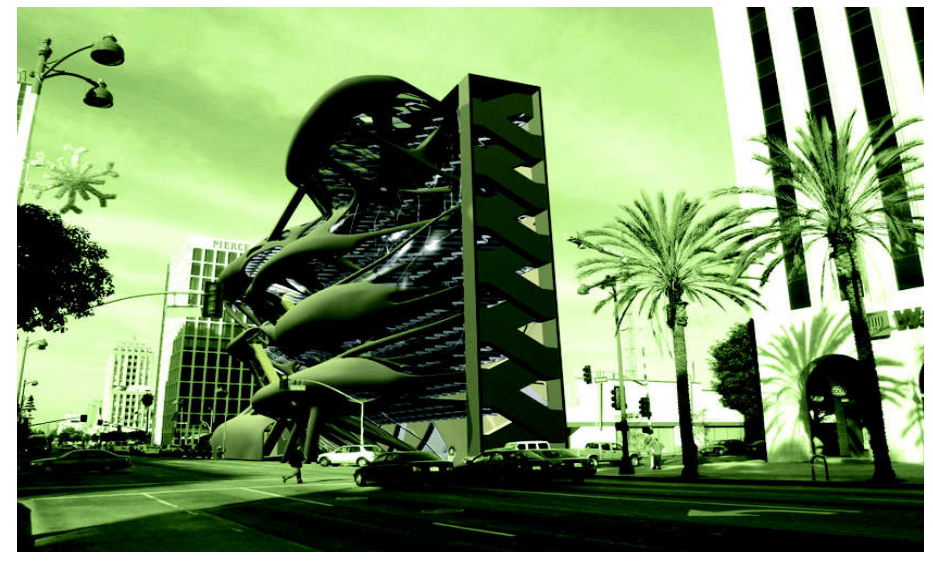

Project 2: Design Studio rendering

specific presentation of Building Information Modeling was included, and a field trip to a construction site also augmented the class.

The second stage of the technology seminar involved the in-depth work of the development of drawings that investigated the technical problems faced in the design studio projects. As the course progressed, students began to apply the information given through the case studies to the development of their projects. To parallel methods used in the design studios, all projects were reviewed in weekly "pin-ups" where the instructors and visiting lecturers provided guidance and input. The following served as "rules of the game" regarding how students worked during the semester:

\section{Design complexity:}

It was important to the goals of the course that students understand that whatever challenges were posed from the source studio projects be taken at face value. That is to say, projects were not allowed to be overly simplified to ease the investigation, rather students were encouraged to try to take the challenges faced and formulate technical solutions. For example, a design studio project that contained a fluid formal language was not allowed to simply be redesigned in a flat planer manner, but instead the students were asked to immediately research what materials and structures would lend themselves to the design aim as outlined in the studio project. This engendered the idea that any investigation of complex formal languages also requires a parallel path of inquiry based on the research of materiality, performance, structural systems, environmental systems, etc. Again, the goal was not to expect that we could teach everything about these topics, but to rather create a situation where the students could experience the breadth of issues as applied to one particular case.

\section{Detailing is design:}

Students were encouraged to understand that the advanced development of the architectural project involved design thinking and innovation. The important aspect that was emphasized was that the course was in many ways a continuum of the design class, yet with a shifted focus to technology. Including well-respected designers to present built projects to the class as mentioned previously helped to demonstrate to the students that "detailing is design." Seeing first hand how contemporary architects progress from concept to built form helped to demystify the technical aspects which can be intimidating to students. This approach was important to communicate to them as they progressed through the projects so that they could understand that the skills encouraged in the design studio were transferrable to the technical investigations they

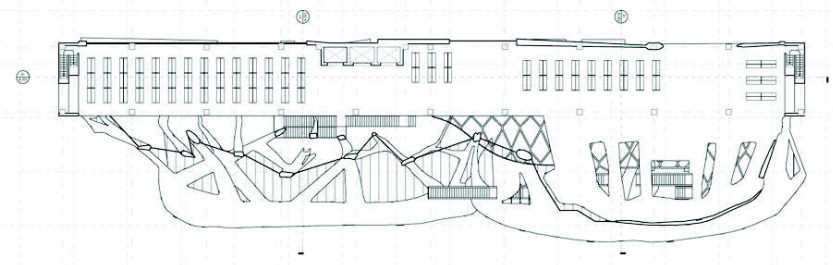

Project 2: Design Studio plan

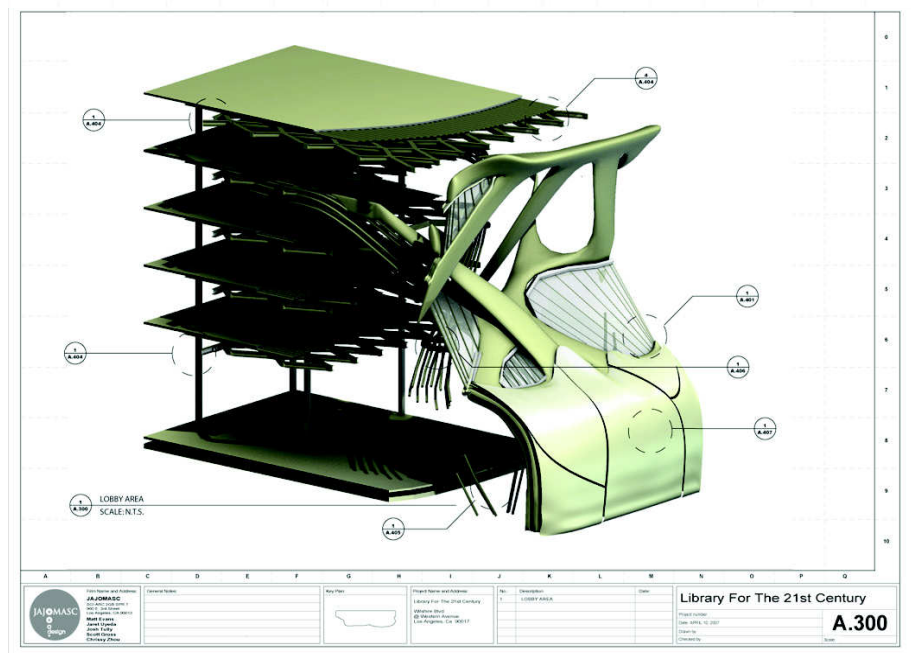

Project 2: Technology Seminar assembly study

were faced with. Since the two technology seminar instructors were part of the design studio team, we were able bridge the discussions from the design studio as they applied these to the technology seminar. A discussion of a particular glazing mullion system over another, for instance, involved not only the technical material aspects of each, but also the phenomenological and conceptual implications as it applied to the overall project. 


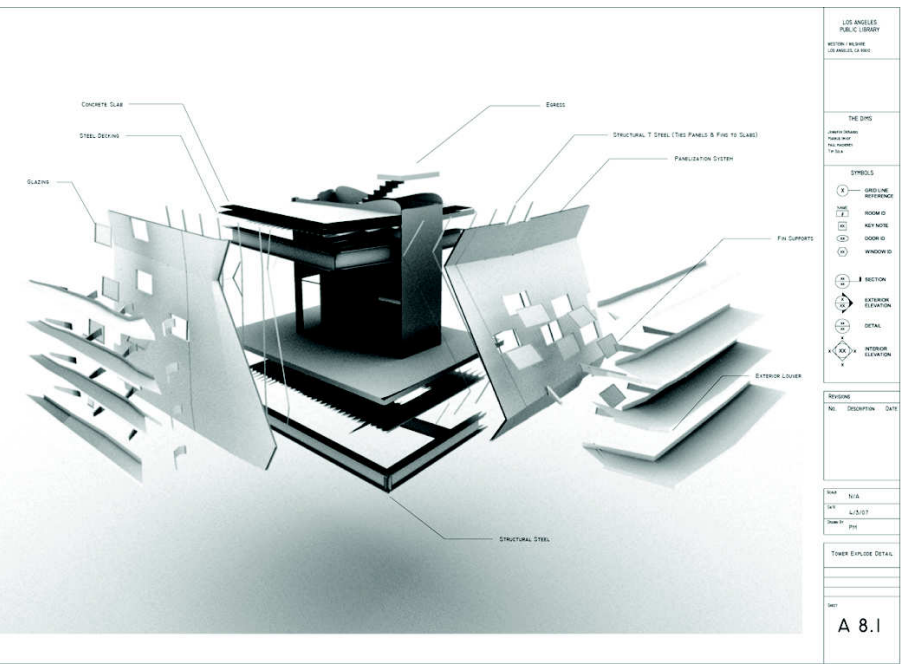

Project 1: Technology Seminar exploded view

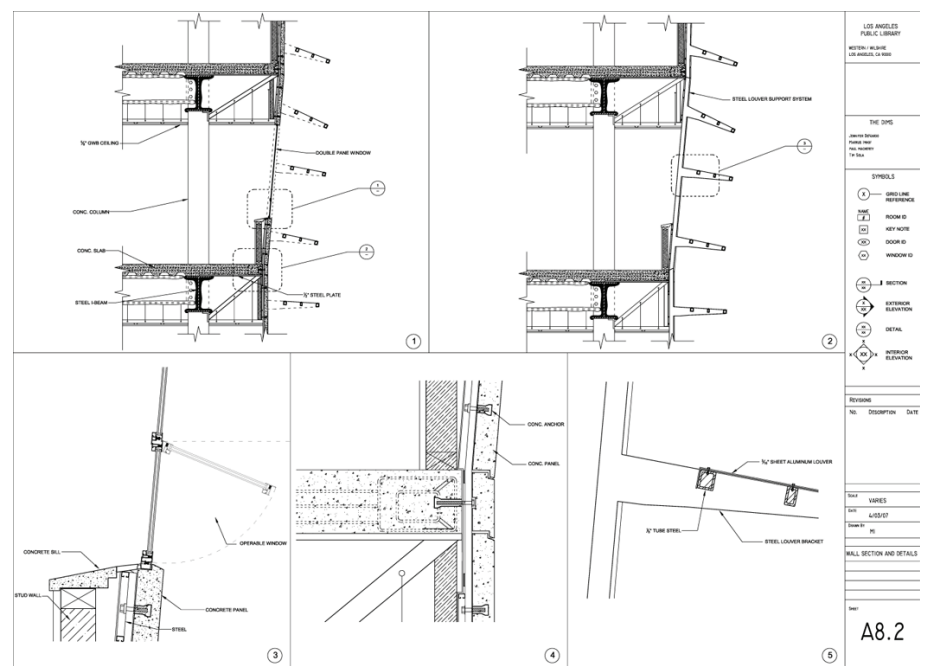

Project 1: Technology Seminar wall sections

\section{D Chunk:}

While the source projects from the design studios were further documented and examined in their entirety regarding egress and fire \& life safety systems, the students were asked to extract a portion of the project (at least two floors and approximately 30' x 30' x 60' in dimension) that represented it's inherent complexity regarding enclosure and building systems. This "3D chunk" served to focus the course on that portion of the building that would be examined. 2D output of all drawings were directly from the 3D model, so each element of the developed project was built in the 3D environment that was shared amongst the student team. It was important to continually emphasize to the students that although they were working in a virtual 3D environment, they were ultimately producing 2D drawings from that environment that would be the basis for describing the complexity of the project in a technical manner.
Understanding this notion that the 2D document, or printed construction document, is still the prevalent representational mode for construction was important to communicate to the students.

\section{Teamwork:}

A conscious emphasis on team building was emphasized as the projects progressed, and students had to present the projects as groups during the semester. Students self-organized the division of work with guidance from the instructors. They had to formulate their own firm name and create a title block for formatting the design documentation. At pin-ups students had to individually discuss their specific role of investigation in the project. Students began to divide the work into systems in many instances, one student developing a structural model, while another may be on glazing systems, while another focused on building panels for example. This dynamic served to demonstrate to the students that

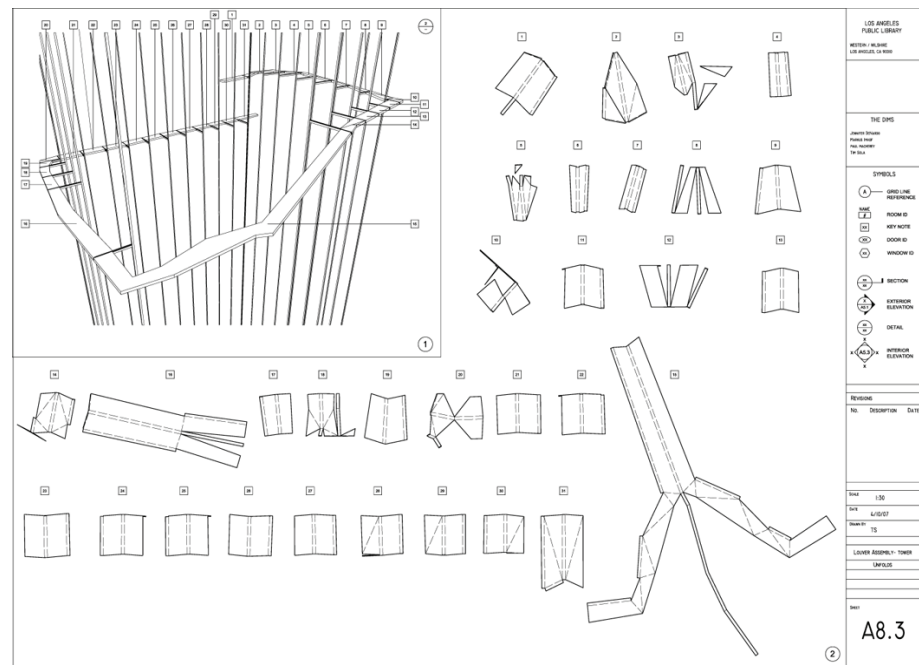

Project 1: Technology Seminar sun shade panel studies

the actions of one within the team affected the actions of another as they began to coordinate the documents and the integration of these building components. This interchange was critical in the learning of not only the complexity of the task at hand, but also of the importance of teamwork between each student as they developed the projects. Perhaps this was even more important than the specific technical "solutions" being attempted, since the students began to understand that these investigations required the interaction and collaboration of team members to be thoroughly designed and documented.

The importance of failure:

Another important aspect was the understanding that any investigation which attempts to challenge conventional notions of architectural form must also accept the importance of failure within the process. This of 


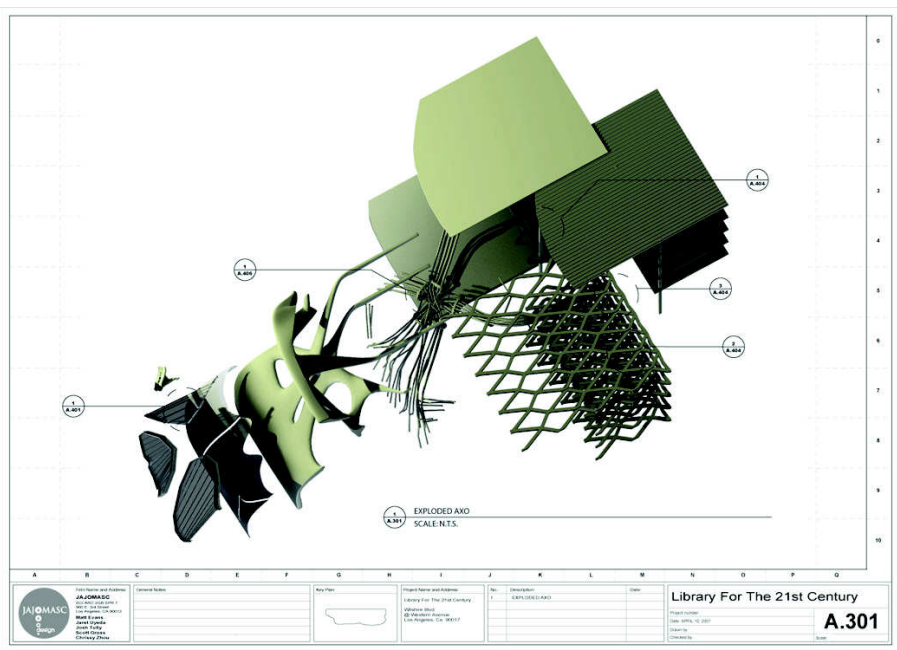

Project 2: Technology Seminar exploded view

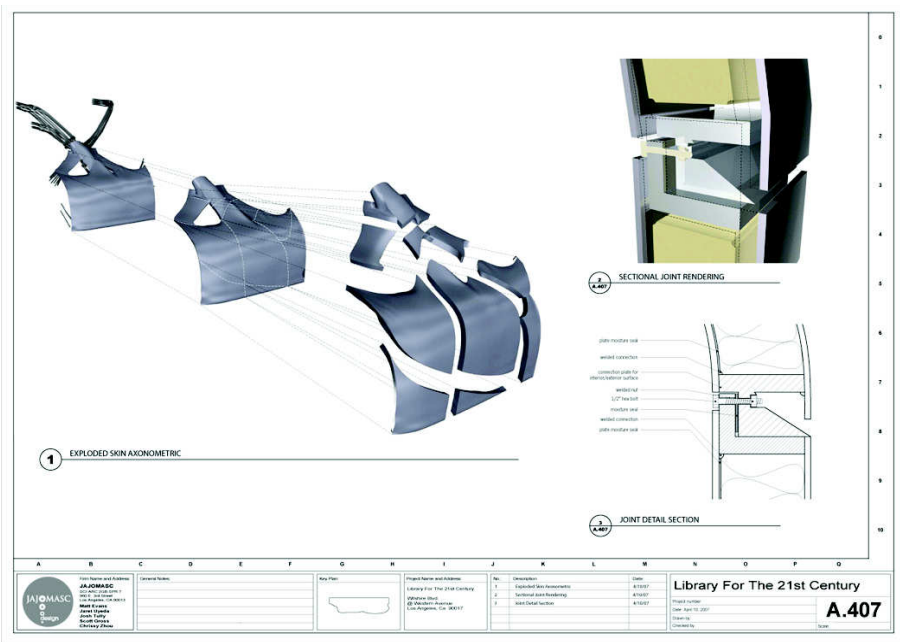

Project 2: Technology Seminar building panel studies

course is not to be confused with the professional aspect of building failure, or leaking roofs, etc., but rather the notion that dead-ends and failed attempts at serious investigations of technical solutions within the academic context serve as important learning models for students. This is fundamentally different than attempting to teach a technology course through strict "how to" methods, instead we encouraged an understanding that as designers, we accept challenges without 'a priori' solutions and that it is the process of testing theorems and concluding from the results that we grow. Some student teams came across this idea as they faced conflicting impulses regarding their understanding of the design project as a conceptual entity versus the technical requirements they were investigating. In this light, the students work in some instances "failed" to reach a level of resolution as compared to a professional standard, but that in the process of attempting to solve a particular problem, the students learned a great deal. At the same time, the overall result of the investigations was quite thorough and demonstrated a high level of technical achievement.

\section{Conclusion and future challenges:}

The results of the coursework, having completed its second year in the curriculum, have demonstrated a new understanding for integrating typically divergent pedagogic stances regarding design and technology. SCl_Arc, which has a longstanding reputation within the design community, has been able to critically examine the role of technology instruction as it relates to the design studios. This work was instrumental in the recent accreditation process that the school experienced and served to focus the curriculum and to create a future model for teaching the class in the undergraduate and post professional programs.

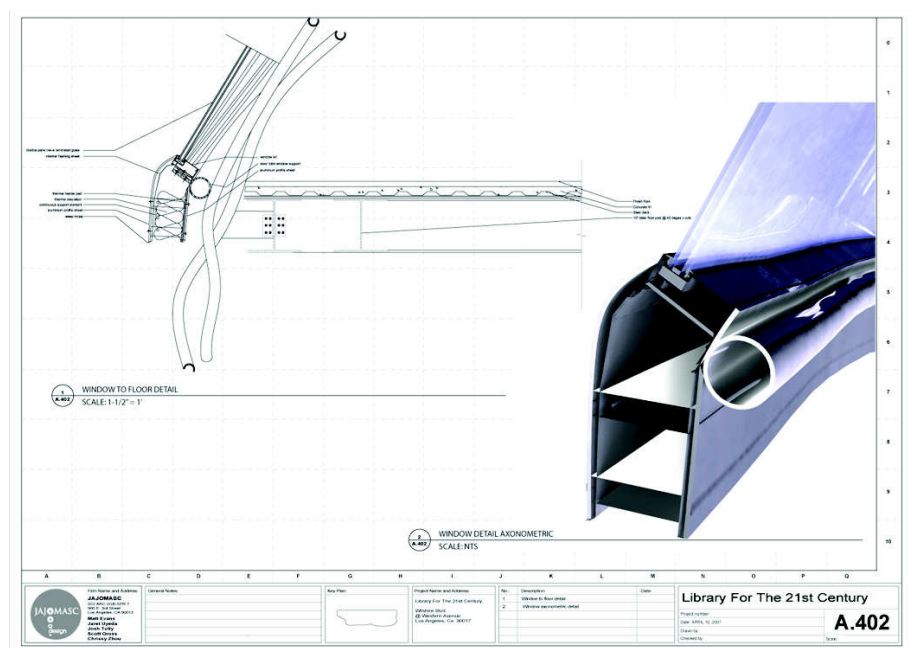

Project 2: Technology Seminar glazing detail

While the use of 3D digital software is fully integrated in the school, the use of more advanced Building Information Modeling techniques has not been fully embraced beyond specialty topic seminars. The advanced nature and complexity of this type of software has thus far inhibited its full adoption within the school. The potential for this integrated application and the associated requirement of deep teamwork skills within the 3D environment are promising, however, and further work needs to be done in order to better prepare students for this inevitable evolution of the dynamic model in practice. One problem that remains a challenge for educators is the continuously changing aspects of differing software platforms within the profession. A further challenge is that Building Information Modeling software is not particularly useful in the design stage of projects, while other 3D platforms are especially useful for design studios. The evolution of these platforms continues and will 


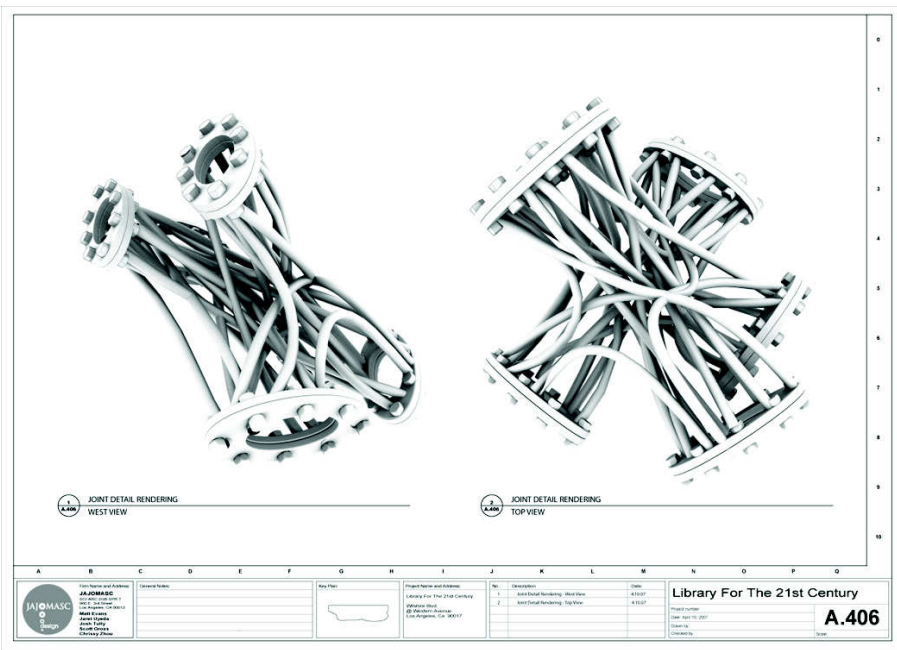

Project 2: Technology Seminar pipe connection study

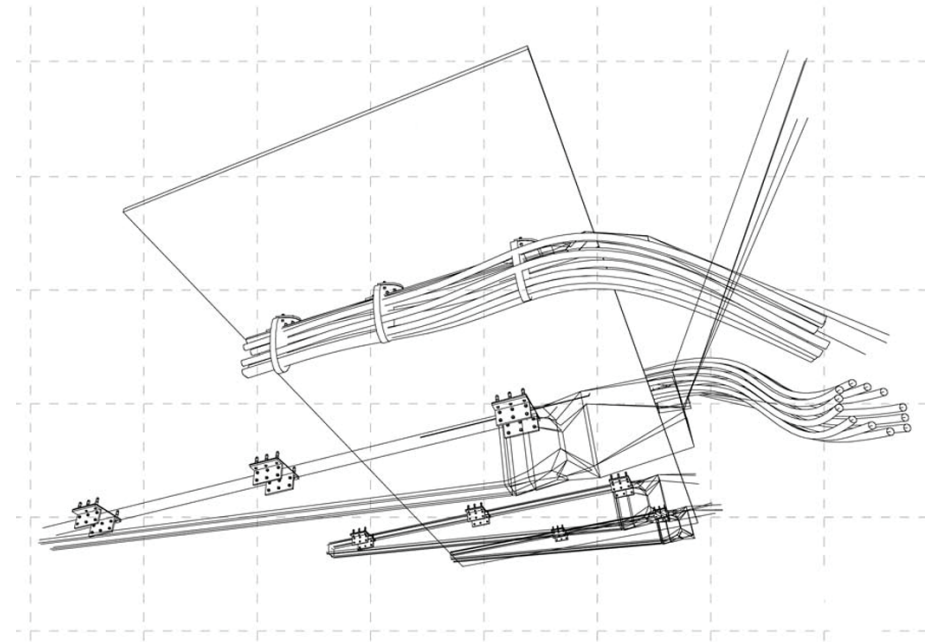

Project 2: Technology Seminar beam assembly study

no doubt merge in the coming years more and more. Until that time, educators and architects alike will continue to have to shift platforms and tools to cater to the specific tasks at hand.

The development of team building within the design and technology courses remains a challenge to students and instructors alike. Standard notions of authorship and individual identity within the design studios need to be sensitively addressed to ensure that learning is both demonstrated and assessed within both the team and the individual student. There were many instances where students had difficulty getting along with team members, and this can have a destructive influence on learning. More attention by the instructors, and perhaps direct instruction on collaboration techniques should be included in the future.
Another challenge to the coursework had to do with the inherent abstract nature of the 3D virtual environment that he students are working in. This has been a challenge for all instructors of architecture since the interface of the computer monitor, the dynamic nature of zooming in and zooming out, and the basic scale-less nature of the digital environment. This was addressed to some success with the student field trips to construction sites. Seeing first hand the components of building construction remains an absolutely critical part of building technology education. Earlier visits to construction sites in the semester would better serve to demonstrate in a tangible way the nature of scale, weight, and dimension of building material. One particular student who was having a difficult time understanding the dimensions and thicknesses of a steel beam was completely affected by touching a large column that was about to be erected. At that moment, the column represented more than a thin line on a screen, for him he immediately understood the weight and dimension of the material.

I have stated that the inherent complexity of the projects were instrumental in challenging the students to go beyond their knowledge of built form. This certainly enabled many students to rise up to the challenge and produce some compelling investigations, however, in that process some less skilled students had extreme difficulty with the course. This caused some to have a harder time working with more advanced students, and some felt left behind in the process, or relegated to less interesting work within the team. This has caused some debate regarding whether this type of course is appropriate within the core curriculum versus as an elective. Great care needs to be continued in both the monitoring if individual student progress with the course, and the understanding of the diverse abilities within the student body. Regarding this aspect, the application of this method in an undergraduate curriculum is particularly challenging. My work at the University of Southern California is focusing on how to attempt this in a modified manner. We are using a more straight-forward reverse engineering approach with undergraduates where a specific Building Information Modeling software is taught and then used in the application of existing precedent projects. Students are also working in teams and collaboration is instrumental, but the base complexity of the specific projects is reduced, while maintaining a robust investigation into built form. This method does not yet bridge the gap between the design studio and it is hoped that in the coming years this will be attempted.

I began this paper with a quote from the architect Thom Mayne regarding the urgency of the changes that are upon the profession. The education of architects will continue to evolve to both reflect the changes in our society and the new technologies that emerge. As educators, it our responsibility to adapt to this change while inventing new methods of learning to prepare students for the future. It does not mean necessarily that we throw everything out and start anew, but rather that we retain proven methods and continue to test new ones, analyzing the successes 
and failures of each. We may be in the midst of a revolution in how architects are conceiving and communicating form, but in conclusion I quote the sociologist Bruno Latour, who while addressing a group of designers stated,

"As I pointed out earlier, the spread of the word 'design' doesn't come at a time when there is less to do; it comes at a time when there is more to do. Infinitely more, since it is the whole fabric of life that is now concerned thanks to the ecological crisis. What no revolution has contemplated, namely the remaking of our collective life on earth, is to be carried out with exactly the opposite of revolutionary and modernizing attitudes. This is what renders the spirit of our time so interesting. President Mao was right after all: the revolution has to be always revolutionalized. What he did not anticipate is that the new 'revolutionary' energy would be taken from the set of attitudes that are hard to come by in revolutionary movements: modesty, care, precautions, skills, crafts, meanings, attention to details, careful conservations, redesign, artificiality, and ever shifting transitory fashions. We have to be radically careful, or carefully radical... What an odd time we are living through."(10)

\section{Acknowledgements:}

Eric Owen Moss, Director of SCl_Arc, and Hsinming Fung, Director of the Graduate Program, were instrumental in their support and guidance in the developing of the coursework. My fellow design studio instructors,

Marcelo Spina, Russell Thomsen, and Tom Wiscombe, were critical in the development of the design studios. Tom Wiscombe, my coteacher of the technology seminar shares equal credit for the work that was achieved in both the design and technology classes. All of the students who

participated in the courses and who are not noted in this paper were instrumental in this effort and without their enthusiasm and effort this of course would not have been possible. The student work illustrated in the paper deserves particular credit too; Project 1: Matt Evans, Jaret Uyeda, Josh Tully, and Scott Gross. Project 2: Chrissy Zhou, Jennifer Denardo, Marcus Imhof, Paul Machery, and Tim Sola.

This work continues at my current position at the University of Southern California, where parallel programs are being developed under the guidance of Dean Qingyun Ma, Vice Dean Amy Murphy, Undergraduate Director Kim Coleman, and my fellow colleagues, Janek Dombrowa, Justin Brechtel, and Mina Chow.

\section{End notes:}

(1) The AIA and collateral organizations have studied the implications of the changes brought about by integrated

practice through conferences and papers, including: AIA's 2005 Reporton Integrated Practice 2006 Integrated Practice Issues Forum,
Oak Park AIA's 2007 Integrated Project Delivery—A Working Definition ACSA/AIA Cranbrook 2007: Integrated Practice and the Twenty-first Century Curriculum

(2) Norman Strong, FAIA, Introduction, Report on Integrated Practice, 2005, an AIA publication.

(3) A Working Definition, Integrated Project Delivery, 2007 AIA California Council.

(4) The following organizations have all begun initiatives, white papers, and committees addressing Building Information, Integrated Project Delivery, and associated standards:

American Institute of Steel Construction (AISC)

American Society for Quality (ASQ)

American Society of Heating, Refrigerating and Air-

Conditioning Engineers (ASHRAE)

American Society of Civil Engineers (ASCE)

American Society of Professional Estimators

Association of General Contractors of America (AGC) -BIMForum

Building Owners and Managers Association (BOMA)

Continental Automated Buildings Association (CABA)

Center for Facilities and Environment (CIFE)

Construction Industry Institute (CII)

Construction Managers Association of America (CMAA)

Construction Owners Association of America (COAA)

Construction Specifications Institute (CSI)

National Association of Home Builders (NAHB)

Project Management Institute Design Procurement

Construction Specific Interest Group (DPC-SIG)

Sheet Metal and Air Conditioning Contractors' National

Association (SMACNA)

Sustainable Buildings Industry Council (SBIC)

U.S. Green Building Council

(5) Ernest L. Boyer and Lee D. Mitgang, Building Community, A New Future for Architecture and Education and Practice, (The Carnegie Foundation for the advancement of Teaching, Princeton, New Jersey, 1996)

(6) Daniel Friedman, FAIA, Report on Integrated Practice, 2005, an AIA publication.

(7) AIA's White Paper for NAAB Accreditation Review Conference, 2007, an AIA publication.

(8) ACSA/AIA Cranbrook 2007: Integrated Practice and the Twentyfirst Century Curriculum, Closing Response, Edward Allen, The American Institute of Architects and Association of Collegiate Schools of Architecture, 2008.

(9) David Leatherbarrow, Performative Architecture Beyond Instrumentality, (Spon Press, New York, NY, 2005), p. 18.

(10) Bruno Latour, A Cautious Prometheus? A Few Steps Toward a Philosophy of Design (with Special Attention to Peter Sloterdijk), Keynote lecture for the Networks of Design meeting of the Design History Society Falmouth, Cornwall, September 3, 2008. 